\title{
SELF-FINANCING ENVIRONMENTAL MECHANISMS
}

\author{
JOERG BREITSCHEIDEL \\ HANS GERSBACH
}

CESIFO WORKING PAPER NO. 1528

CATEGORY 8: RESOURCES AND ENVIRONMENT

August 2005

\footnotetext{
An electronic version of the paper may be downloaded

- from the SSRN website:

www.SSRN.com

- from the CESifo website:

www.CESifo-group.de
} 


\title{
SELF-FinANCING ENVIRONMENTAL MECHANISMS
}

\begin{abstract}
We explore the design of self-financing tax/subsidy mechanisms to solve hold-up problems in environmental regulation. Under Cournot competition, announcing the subsidy rate seems to be preferable to announcing the tax rate. Moreover, for constant marginal damage the hold-up problem can always be solved by setting subsidies. Under Bertrand competition, only announcing the tax rate can induce at least one firm to invest. We suggest that feebate systems in the automotive sector should be designed as self-financing tax/subsidy mechanisms.
\end{abstract}

JEL Code: D43, D62, L50, Q28.

Keywords: hold-up problems, environmental regulation, taxes and subsidies, self-financing mechanisms, emission control.

\author{
Joerg Breitscheidel \\ Centre for European Economic Research \\ $\mathrm{GmbH}, \mathrm{L7.1}$ \\ 68161 Mannheim \\ Germany \\ joerg.breitscheidel@lycos.de
}

\author{
Hans Gersbach \\ Alfred-Weber-Institute \\ University of Heidelberg \\ Grabengasse 14 \\ 69117 Heidelberg \\ Germany \\ gersbach@uni-hd.de
}

We would like to thank Till Requate, Jürgen Eichberger, Cees Withagen, Sjak Smulders, seminar participants in Tilburg and Heidelberg, and participants at the 2nd World Congress of Environmental and Resource Economists in Monterey 2002, and at the Annual Congress of the German Economic Association in Innsbruck 2002 for helpful comments and suggestions. 


\section{Introduction}

Self-financing tax/subsidy mechanisms can be a powerful policy tool to spur welfare-enhancing investments in oligopolies. Consider environmental regulation settings, where firms can make costly investments in non-polluting technologies. Firms may behave strategically by refusing to invest, saving investment costs, and hoping to force the regulator to adopt looser regulations. Self-financing tax/subsidy mechanisms treat firms alike, whether they invest or not. If, however, one firm invests and the other does not, the firm that does not comply must pay taxes, which are used in turn to subsidize the complying firm. This potentially creates a Prisoner's Dilemma for firms, and an equilibrium may exist in which all firms invest to avoid subsidizing others. The regulator can credibly trigger investments in emission reductions.

Hold-up problems are real-world phenomena. For instance, the standards specified by the 1970 American Clean Air Act were repeatedly delayed. Most dramatically, faced with industry claims that the proposed emission standards would shut down factories, Congress amended the Act in 1977, thus both weakening and postponing the standards. Similarly, in 1988 the government delayed standards for the 1989 model year. Further evidence of the hold-up problem can be found in Weimann (1995), who illustrates how the "cartel of silence" on the part of engineers prevents the government from imposing tighter regulations.

Another recent example illustrates credibility problems. In 1998, Congress included a provision in the highway bill that delayed the first steps towards bringing states into compliance with the Clean Air Act's long-standing goal of "reasonable progress" toward eliminating man-made haze in specially protected areas for six to nine years. Until Congress intervened, the Environmental Protection Agency had planned to ask states to file preliminary plans by 1999, showing how they would eventually raise visibility standards gradually over the next few decades by complying with the new rules that had been proposed two years earlier. ${ }^{1}$

Hold-up problems occur when an announced policy is not time consistent and firms behave accordingly. If firms believe that the government will loosen environmental policy or reduce the promotion of environmentally

\footnotetext{
${ }^{1}$ See New York Times, May 27, 1998.
} 
friendly technologies, they are likely to invest little in such technologies. For instance, in 2002 the UK government thought about changing the rules on the eligibility of co-firing biomass with coal. This change would reduce the renewable obligation certificate price and therefore reduce the profitability and the amount of investment in renewable energy production. ${ }^{2}$

We consider two models for self-financing regulatory mechanisms when hold-up problems are present. In the first one, two firms produce homogenous goods, have the possibility of investing in emission reduction, and compete in the product market in a Cournot fashion. Our main results are as follows:

Under Cournot competition it is possible that the announcement of the tax rate will yield the investment of all firms, whereas the announcement of the subsidy rate will not, and vice versa. If the emission damage is linear, then the announcement of the subsidy rate will yield the investment of all firms. Announcing the subsidy rate seems to be preferable to announcing the tax rate if there is a hold-up problem.

In the second model, we consider Bertrand competition with homogenous goods. Under Bertrand competition announcing the subsidy rate does not work, whereas announcing the tax rate leads to an investment by one firm. It is not possible to induce both firms to invest by using a self-financing mechanism.

Our mechanism might be applied as a feebate system in the automotive sector to promote the sale of environmentally friendly cars. Feebates refer generally to fees on fuel-inefficient vehicles and rebates on fuel-efficient ones. A first option of a feebate-system is taxation of the purchase of cars that exceed a certain emission level, and to refund the tax revenues to the buyers of cleaner cars. A second option is the implementation of a feebate system at the industry level, which would be equivalent to our tax/subsidy mechanism. The production of environmentally friendly cars could be subsidized by using the revenues from the taxation of the production of environmentally harmful cars.

The revenue neutrality can be quite important in determining public opinion and political support for feebates (see Bernow, 2002). Different feebatesystems have been tested in the automotive sector. One example of a widely applied design of a feebate system were the German tax differentials for

\footnotetext{
${ }^{2}$ See DTI (2003) and Helm et al. (2003).
} 
catalytic converters and unleaded gasoline, which were implemented in 1986. Cash subsidies, grants and a repayment for installation of catalytic converters for the produced cars with analytic converters have been offered by the government, combined with taxes on leaded gasoline (see Bernow, 2002). Such feebate schemes are generally not revenue-neutral. One of the strengths of our mechanism is that it is revenue neutral by construction; no regulation adjustment is needed.

One possible approach for the practical design of our mechanism for the automotive industry is the following: Each car manufacturer has to pay a certain tax rate for the sale of each environmentally harmful car in one period. At the end of this period, the tax revenues are paid as a subsidy to the car manufacturers in proportion to the amount of environmentally friendly cars sold within that period, such that total tax revenues equal total subsidy outlays. In other words, the subsidy rate is determined endogenously by the self-financing condition. ${ }^{3}$ In addition, one could allow for a differentiation between different categories of environmentally friendly and harmful cars and accordingly, a differentiation of tax rates and subsidy rates. One would then fix the set of tax rates and the relative subsidy rates. The absolute level of the subsidies would be determined endogenously by the self-financing condition. Train et al. mention possible feebate schedules which take into account the level of environmental friendliness/harmfulness of the cars. One example is a schedule which is linear in the miles per gallon.

Feebate systems can yield substantial emission reductions. In HLB (1999) it is reported that a feebate system in the Canadian automobile market could cut down greenhouse gas emissions by 33.95 mega-tones over a 22 -year period. ${ }^{4}$

The paper is organized as follows: Section 2 gives an overview of the related literature and section 3 develops the basic model. Section 4 describes Cournot competition, while Section 5 describes Bertrand competition. Section 6 is the conclusion.

\footnotetext{
${ }^{3}$ The tax revenues are simply refunded to the tax payers if no environmentally friendly car was sold within the period.

${ }^{4}$ There are also other potential real world applications of tax/subsidy schemes. Tax/subsidy schemes might be used to reduce the consumption of water and other resources and as a way to improve the energy efficiency of new buildings.
} 


\section{Relation to the Literature}

Our paper relates to different strands of literature. Gersbach (2002) has suggested self-financing tax/subsidy schemes in environmental regulation. The recent paper contains three novel considerations. First, we define a general tax/subsidy mechanism when firms compete à la Cournot and holdup problems in environmental regulation are present. Second, we distinguish between announcing the tax and the subsidy rate which turns out to be important for the scope of the mechanism. Third, we develop tax/subsidy mechanisms for Bertrand competition.

Additionally, our paper is related to the literature about the original hold-up problem, where a firm facing a single buyer may find investment unprofitable if, after making the investment, the buyer offers to pay only marginal costs. This has been discussed in Klein, Crawford and Alchian (1978), Joskow (1987), Williamson (1983), and in the incomplete-contract literature (see the survey by Hart, 1995).

The idea that threats or promises by the government may not be credible has already been discussed in literature on trade protection (Staiger and Tabellini, 1987, Matsuyama, 1990, Tornell, 1991), regulation of utilities (Salant and Woroch, 1992, Gilbert and Newbery, 1994, Urbiztondo, 1994), and privatization (Levy and Spiller, 1997). The hold-up problem is only solvable if there are means which make governmental regulation credible. In our paper, we design a credible self-financing tax/subsidy scheme to spur investments by firms.

Our analysis also relates to mechanism design that uses the tools of multistage games and subgame perfect equilibria (see Varian, 1994 or Moore, 1992 for a review of the literature). Our paper is an example of subgame perfect implementation of environmental regulation.

Finally, our paper is related to work about the incentives to adopt clean technologies in the design of environmental policy instruments. Milliman and Prince (1989) and Jung, Krutilla and Boyd (1996) examine firms' incentives to invest in new technology, and provide a ranking of different policy instruments (see also Laffont and Tirole, 1996, Requate 1995). Recently, Requate and Unold (2003) have established a precise hierarchy of policy instruments when firms have no impact on the level of environmental regulation. In our 
context, we examine incentives under tax/subsidy mechanisms to invest in clean technologies when a firm can influence the tightness of regulation by its investment decision.

\section{$3 \quad$ The Model}

\subsection{Firms and Welfare}

We consider an industry with two firms denoted by $i=1,2$ producing a homogeneous good. The marginal cost of production is $c(c \geq 0)$, and is independent of the installation of abatement technology. The investment decisions of firms are denoted by $I_{i}, i=1,2$ with

$$
I_{i}=\left\{\begin{array}{ll}
K & \text { if firm } i \text { invests } \\
0 & \text { if firm } i \text { does not invest }
\end{array} .\right.
$$

Similarly,

$$
a_{i}= \begin{cases}a & \text { if firm } i \text { has not invested } \\ 0 & \text { if firm } i \text { has invested }\end{cases}
$$

denote emissions per unit of output depending on the investment decisions of firms. Firms can reduce the emissions per unit of output from $a>0$ to zero by investing a fixed amount of $K$ in clean technologies. Not-investing firms therefore are also called polluting firms, while investing firms are also called clean or not polluting firms. We denote by

$$
E=a_{1} q_{1}+a_{2} q_{2}
$$

the resulting total amount of emissions, where $q_{i}$ denotes the output of firm $i$.

$$
Q=q_{1}+q_{2}
$$

is the industry's output. Social welfare depends on consumer surplus $S(Q)$, on producer surplus net of investment costs $P(Q)$, on investment outlays $I_{1}+I_{2}$ and on the social costs of emissions $D(E) . D(E)$ is the social damage in terms of willingness to pay. Therefore, social welfare, as denoted by $W$, is given by

$$
W=S(Q)+P(Q)-I_{1}-I_{2}-D(E) .
$$


A number of comments are necessary here. Our central assumption is that firms cannot be punished directly for not investing. It is impossible for the government to force firms to invest by penalizing non-investing firms financially, or by closing them down. As discussed at length in the literature on incomplete contracts (see Hart (1995) for a survey), even when investments are observable, they are not verifiable in courts, and hence penalties directly dependent on investment behavior are not feasible. This is the case, for example, when investment in clean technologies is a by-product of other investments, or when investment requires certain types of human capital for implementation. In the latter case, firms can always claim that they are not able to generate the full benefits of an investment. A clear example of nonverifiable investments are $R \& D$ efforts. Our model is applicable to $R \& D$, where the success probability is high. In our case this probability is assumed for convenience to be one.

Although the regulator is unable to directly regulate the adoption of clean technology, he can levy taxes on firms that have high emissions and can pay subsidies to firms with low emissions per unit. Hence, taxes and subsidies can be made contingent on emissions per unit of output and therefore indirectly on investment in less polluting technologies. Finally, we note that the regulator can commit to using a certain framework for environmental regulation. In particular, we assume that the regulator is constrained to use taxes and subsidies in regulation emissions. Other regulatory frameworks such as permit markets are excluded. ${ }^{5}$ This assumption is justified by the time a regulator needs to develop a regulatory framework. Once such a framework has been developed and has become law, it commits a regulator for a certain time. The actual level of taxes or subsidies, however, can be adjusted frequently and we assume precisely that the regulator will adjust tax or subsidy rates in order to maximize social welfare.

We assume that the regulator maximizes social welfare given in equation (5). Hence, the regulator does not pursue revenue objectives in order to focus on solving hold-up problems. In turn, our self-financing constraint ensures that no funds from the government budget are needed. The tax/subsidy mechanism below could be adapted to include revenue objectives by considering the shadow costs of taxation in the economy. The scope for solving the

\footnotetext{
${ }^{5}$ The role of permit markets in solving hold-up problems is discussed in Gersbach and Glazer (1999).
} 
hold-up problem would, however, decrease. Third, our model set-up is very simple. In the final section, we comment on the robustness of our conclusions with respect to the availability of completely clean technologies and to uncertainty.

Before introducing the tax/subsidy mechanism we note that the regulator pursues goals which might be competing. In order to generate strong investment incentives, polluting firms should face a tight regulation. On the other hand, the regulation should limit product market distortions which calls for soft regulation.

\subsection{The Tax/Subsidy Mechanism}

We consider the following four-stage regulatory tax/subsidy mechanism:

- Stage 1: The government commits to using the following self-financing tax/subsidy scheme:

Table 1:

\begin{tabular}{|l|l|}
\hline (i) Both firms pollute & Emissions tax $\tau$ \\
\hline (ii) One firm pollutes & $\begin{array}{l}\text { Subsidy to the clean firm, financed } \\
\text { by the taxation of the polluting firm } \\
\text { (tax/subsidy rule) }\end{array}$ \\
\hline (iii) No firm pollutes & No taxes or subsidies \\
\hline
\end{tabular}

If both firms pollute, the regulator passes on the gains from taxation as a lump-sum transfer to the consumers. If only one firm pollutes, the tax/subsidy rule is used, and we have: The clean firm is subsidized by $s$, which denotes the subsidy per unit of product sold, while the polluting firm is taxed by $t$, which denotes the emission tax per unit of product sold. The regulator has two choices. He can announce a subsidy rate denoted by $s^{a n n}$, or he can announce a tax rate denoted by $t^{a n n}$. To describe subsidization and taxation, suppose that firm 1 does not pollute and firm 2 does. Then, the regulation of the two possible scenarios is as follows: 
1. The regulator announces the subsidy rate $s^{a n n}$ : Net profits $\Pi_{1}$ and $\Pi_{2}$ are realized. The polluting firm 2 has to pay the tax rate

$$
t= \begin{cases}\min \left\{s^{a n n} q_{1}, \max \left\{\Pi_{2}^{*}, 0\right\}\right\} / q_{2} & \text { if } q_{2}>0 \\ 0 & \text { else }\end{cases}
$$

and the clean firm 1 is subsidized by the rate

$$
s=\left\{\begin{array}{ll}
\min \left\{s^{a n n}, \max \left\{\Pi_{2}^{*} / q_{1}, 0\right\}\right\} & \text { if } q_{1}>0 \\
0 & \text { else }
\end{array},\right.
$$

whereby $\Pi_{2}^{*}$ denotes the second firm's pretax net profit (the net profit without consideration of tax payment $t q_{2}$ ). By these rules the regulator always ensures that the self-financing condition (the gains from taxation equal the subsidy outlays) is fulfilled in all circumstances, that is, any combination of $q_{1}, q_{2}$ and $s^{a n n}$. Therefore there are no incentives for firm 2 to attempt to violate the self-financing condition. If the implementation of $s^{a n n}$ would violate the self-financing condition, given the production quantities $q_{1}$ and $q_{2}$, rules (6) and (7) would lead to a downward adjustment of $s$ and $t$ until the self-financing condition is fulfilled.

2. The regulator announces the tax rate $t^{a n n}$ : Net profits $\Pi_{1}$ and $\Pi_{2}$ are realized. The regulator taxes the polluting firm 2 by the tax rate

$$
t= \begin{cases}\min \left\{t^{a n n}, \max \left\{\Pi_{2}^{*} / q_{2}, 0\right\}\right\} & \text { if } q_{2}>0 \\ 0 & \text { else }\end{cases}
$$

and subsidizes the clean firm 1 by the subsidy rate

$$
s= \begin{cases}\min \left\{t q_{2}, \max \left\{\Pi_{2}^{*}, 0\right\}\right\} / q_{1} & \text { if } q_{1}>0 \\ 0 & \text { else }\end{cases}
$$

whereby $\Pi_{2}^{*}$ again denotes the second firm's pretax net profit. As before, rules (8) and (9) provide for the fulfillment of the selffinancing condition.

- Stage 2: Firms decide whether or not to invest in emissions reduction.

- Stage 3: The government uses the tax/subsidy scheme and sets $\tau$ or $s^{a n n}$ or $t^{a n n}$. 
- Stage 4: Firms compete and produce. ${ }^{6}$

In the following, we study the tax/subsidy mechanism for Cournot-type competition. Our key question is: Should the regulator announce the subsidy or the tax rate in the tax/subsidy mechanism to solve the hold-up problem?

\section{Cournot Competition}

We assume that the firms stand in Cournot competition, and choose their production quantities $q_{1} \geq 0$ and $q_{2} \geq 0$. The inverse demand function is given by

$$
p(Q)=1-b Q .
$$

$b$ is a positive constant. Marginal costs $c$ are assumed to be lower than 1 and nonnegative, otherwise production would not take place. Therefore production costs of firm $i(i \in\{1,2\})$ are given by $c q_{i}$.

Note that the total tax burden of the non-investing firm is of a lumpsum nature, given the subsidy rate $s^{a n n}$, the production quantity of the firm investing, and given that the profit of the non-investing firm exceeds or equals the tax burden.

To keep the model simple, we assume as a tie-breaking rule that a firm will choose the highest production quantity if it has more than one optimal alternative.

\subsection{Standard Emission Taxation}

In real world environmental problems, the emissions taxation is a very popular instrument. In this section, we suppose that the regulator imposes emissions taxes on the output. The tax rate is of the welfare-maximizing kind and depends on the number of firms polluting. The gross profit (product market profit) of firm $i$ is denoted by $\pi_{i}^{I_{1} I_{2}}$, where $I_{1}$ and $I_{2}$ respectively denote the investment decisions by the first and the second firm. Similarly,

\footnotetext{
${ }^{6}$ Each firm is allowed to exit.
} 
the production quantity of firm $i$ is denoted by $q_{i}^{I_{1} I_{2}}$. We now consider each case in turn.

First, let us suppose that no firm has invested. The optimal tax rate is denoted by $t^{0}$ and can be zero or positive. The tax revenues are distributed to consumers as a lump-sum transfer. The profit of firm $i(i \in\{1,2\})$ is denoted by $\pi_{i}^{00}$, and given by

$$
\pi_{i}^{00}=\left((1-b Q)-c-t^{0}\right) q_{i} .
$$

The firms choose the following quantities in the unique equilibrium:

$$
q_{1}^{00}=q_{2}^{00}=\frac{1-c-t^{0}}{3 b},
$$

whereby $t^{0} \in[0,1-c] . q_{1}^{00}$ is zero for $t^{0}=1-c$. The gross profits are given by

$$
\pi_{1}^{00}=\pi_{2}^{00}=\frac{\left(1-c-t^{0}\right)^{2}}{9 b} .
$$

The regulator has to choose $t^{0} \in[0,1-c]$ to maximize social welfare, which is given by

$$
W=\frac{b}{2}\left(2 q_{1}^{00}\right)^{2}+2 t^{0} q_{1}^{00}+2 \pi_{1}^{00}-D\left(2 a q_{1}^{00}\right) .
$$

Second, suppose one firm (say firm 1) has invested, while the other has not. In this case, the regulator again sets an emission tax per unit of output, if this output generates emissions. We denote the welfare-optimizing tax rate in this case by $t^{K}$, which will only be applied to polluting output, and thus only to firm $2 .^{7} t^{K}$ is situated in the interval $\left[0, \frac{1-c}{2}\right]$. Accordingly, production quantities and profits are given by

$$
\begin{gathered}
q_{1}^{K 0}=\frac{1-c+t^{K}}{3 b}, \quad q_{2}^{K 0}=\frac{1-c-2 t^{K}}{3 b}, \\
\pi_{1}^{K 0}=\frac{\left(1-c+t^{K}\right)^{2}}{9 b}, \pi_{2}^{K 0}=\frac{\left(1-c-2 t^{K}\right)^{2}}{9 b} .
\end{gathered}
$$

The regulator has to choose $t^{K} \in\left[0, \frac{1-c}{2}\right]$ to maximize social welfare which is given by

$$
W=\frac{b}{2}\left(q_{1}^{K 0}+q_{2}^{K 0}\right)^{2}+t^{K} q_{2}^{K 0}+\pi_{1}^{K 0}+\pi_{2}^{K 0}-K-D\left(a q_{2}^{K 0}\right) .
$$

\footnotetext{
${ }^{7}$ There are no tax payments for firm 1 since it does not cause emissions.
} 
Third, suppose that both firms have invested. Then, since no emissions are generated, the emission tax is zero. In this case production quantities and profits are given by

$$
\begin{gathered}
q_{1}^{K K}=q_{2}^{K K}=\frac{1-c}{3 b}, \\
\pi_{1}^{K K}=\pi_{2}^{K K}=\frac{(1-c)^{2}}{9 b} .
\end{gathered}
$$

Now we are in a position to formulate the hold-up problem. In an intermediate step, we characterize a situation, which is called "optimal full investment".

Definition 1 The situation

$$
\begin{aligned}
K & <\pi_{1}^{K K} \text { and } \\
W_{2} & >\max \left\{W_{0}, W_{1}\right\}
\end{aligned}
$$

is denoted by "optimal full investment" (OFI). $W_{n}$ denotes the social welfare if $n$ firms have invested, and emissions are taxed optimally.

Therefore, OFI exists if the following two statements are fulfilled. The first condition simply states that investment yields higher profits than exiting. Additionally, it is socially desirable in an emission taxation regime for both firms to invest. This is realized in the second condition.

The standard emission taxation yields the investment of both firms if

$$
K<\min \left\{\pi_{1}^{K 0}-\pi_{1}^{00}, \pi_{2}^{K K}-\pi_{2}^{K 0}\right\} .
$$

Definition 2 The hold-up problem (HUP) exists if

$$
\begin{aligned}
& \text { OFI holds and } \\
& K>\min \left\{\pi_{1}^{K 0}-\pi_{1}^{00}, \pi_{2}^{K K}-\pi_{2}^{K 0}\right\} .
\end{aligned}
$$

Thereore, the hold-up problem exists if the investment of both firms is not an equilibrium under the standard emissions taxation in OFI. 
Note that our definition is in the spirit of the traditional hold-up problem concerning the buyer/seller relationship, when the initial investor does not reap all benefits from his investment, and thus investment is below the socially desired level.

In the next section, we examine how firms can be induced to invest if HUP (or OFI) holds.

\subsection{The Tax/Subsidy Mechanism with the Announce- ment of the Subsidy Rate}

We first examine the case in which the regulator uses the tax/subsidy mechanism, and announces the subsidy rate.

\subsubsection{Only One Firm Invests}

We consider the case when only one firm (say firm 1) has invested. The subsidy rate $s^{a n n}$ is announced. According to the definition, $s=s^{a n n}$ holds if the second firm is able to pay the tax burden implied by $s^{a n n}$. To simplify the exposition, we assume that the regulator only announces subsidy rates that, if implemented, would not violate the self-financing condition given firms equilibrium reactions to the announced rates. ${ }^{8}$ Note that the second firm will not try to violate the self-financing condition as long as its net profit, denoted by $\Pi_{2}$, is nonnegative. ${ }^{9}$ Therefore we restrict ourselves to the case $s=s^{a n n} \cdot{ }^{10}$ The self-financing condition implies

$$
s q_{1}=t q_{2} .
$$

Hence the implied tax rate for the second firm is given by

$$
t=s \frac{q_{1}}{q_{2}} .
$$

Remember that the total tax burden of the second firm $t q_{2}=s q_{1}$ is of a lump-sum nature, given the values of $s$ and $q_{1}$.

\footnotetext{
${ }^{8}$ This does not affect our results, since higher subsidy rates would be adjusted accordingly until self-financing holds.

${ }^{9}$ For details of the second firm's behaviour, see proof of proposition 1 in the appendix.

${ }^{10}$ In all cases we will have $\Pi_{2} \geq 0$.
} 
The net profits are given by

$$
\Pi_{1}=(1-b Q-c+s) q_{1}-K, \quad \Pi_{2}=(1-b Q-c) q_{2}-s q_{1},
$$

whereby $\Pi_{1}$ denotes the net profit of the first firm. It is straightforward to demonstrate that in order to maximize profits firms will choose the following quantities:

$$
q_{1}=\frac{1-c+2 s}{3 b}, \quad q_{2}=\frac{1-c-s}{3 b}
$$

Therefore, $0 \leq s \leq 1-c$ must hold. The resulting net profits for the two firms are

$$
\Pi_{1}=\frac{(1-c+2 s)^{2}}{9 b}-K, \quad \Pi_{2}=\frac{1-c(2-c)-5(1-c) s-5 s^{2}}{9 b} .
$$

The profit of the second firm is decreasing in $s$ :

$$
\frac{\partial \Pi_{2}}{\partial s}=-5 \frac{1-c+2 s}{9 b}=-\frac{5}{3} q_{1}<0
$$

We denote the subsidy rate $\frac{3 \sqrt{5}-5}{10}(1-c)$ by $s^{*}$. This is the highest possible implemented subsidy rate because $\Pi_{2}\left(s^{*}\right)=0 . \quad s \leq 1-c$ is fulfilled, since $\frac{3 \sqrt{5}-5}{10}<1$. The regulator will not announce a higher subsidy rate than $s^{*}$ since $\Pi_{2}\left(s^{*}\right)$ becomes negative otherwise. Therefore $s$ has to be situated in the interval $\left[0, s^{*}\right]$. The first firm becomes a monopolist for a higher $s$ than $s^{*}$. If the regulator announces $s=s^{*}$, then the resulting values are

$$
\begin{gathered}
q_{1}=\frac{1-c}{\sqrt{5} b}, \quad q_{2}=\frac{(5-\sqrt{5})(1-c)}{10 b}, \\
\Pi_{1}=\frac{(1-c)^{2}}{5 b}-K, \quad \Pi_{2}=0 .
\end{gathered}
$$

We next investigate the welfare-optimizing subsidy. The sum of consumer surplus and producer surplus is

$$
S+P=\frac{b}{2}\left(\frac{2(1-c)+s}{3 b}\right)^{2}+\frac{(1-c+2 s)^{2}+1-c(2-c)-5(1-c) s-5 s^{2}}{9 b} .
$$

This sum is monotonically increasing in $s$, since

$$
1-c-s>0 \quad \forall s \in\left[0, s^{*}\right]
$$


and therefore

$$
\frac{\partial(S+P)}{\partial s}=\frac{1-c-s}{9 b}=\frac{1}{3} q_{2}>0 \quad \forall s \in\left[0, s^{*}\right] .
$$

The social damage of emissions $D(E)$ is monotonically increasing in $E$, and the emissions $E$ are monotonically decreasing in $s$, since

$$
\frac{\partial E}{\partial s}=-\frac{a}{3 b}<0 \quad \forall s \in\left[0, s^{*}\right]
$$

To sum up, social welfare is monotonically increasing in $s$ for $s \in\left[0, s^{*}\right]$. In particular,

$$
\frac{\partial W}{\partial s}=\frac{1-c-s}{9 b}+\frac{\partial D(E)}{\partial E} \frac{a}{3 b}>0 .
$$

Therefore, the corner solution $s=s^{*}$ maximizes social welfare, and the regulator should announce $s=s^{*}$.

\subsubsection{Equilibria}

We next derive the subgame perfect equilibrium of the four-stage game which, because of the property $\frac{\partial W}{\partial s}>0$, must necessarily involve $s=s^{*}$ if one firm invests and the other does not. An equilibrium is characterized by $I_{1}, I_{2}$, $q_{1}, q_{2}$ and possibly $\tau$ or $s$. The investment decisions $I_{i}$ and the production quantities $q_{i}$ are observable for sure. The regulator has to announce $\tau$, which denotes the tax rate if no firm has invested, in the case of $I_{1}=I_{2}=0$; he has to announce $s$ in the case of $I_{1} \neq I_{2}$.

In the appendix we show:

Proposition 1 Assume $H U P$ and $K<\frac{9}{5} \pi_{1}^{K K}-\pi_{1}^{00}$. Then

1. There exists a unique subgame perfect equilibrium

$$
\left(I_{1}=I_{2}=K, q_{1}=q_{2}=\frac{1-c}{3 b}\right),
$$

supported by

$$
\tau=t^{0}, s=s^{*}
$$


2. If $I_{1} \neq I_{2}$, then $\forall s \in\left[0, s^{*}\right]$ :

$$
\frac{\partial(S+P)}{\partial s}>0
$$

and

and therefore

$$
\frac{\partial E}{\partial s}<0
$$

$$
\frac{\partial W}{\partial s}>0
$$

Proposition 1 indicates that, as long as $K<\frac{9}{5} \pi_{1}^{K K}-\pi_{1}^{00}$, announcing the subsidy rate solves the hold-up problem. Solving HUP means that the regulation yields $I_{1}=I_{2}=K$ in the unique subgame perfect equilibrium. Intuitively, if a firm deviates by $I_{i}=0$ it will encounter zero profits, because it is credible for the regulator to implement $s^{*}$, and to impose taxes on the deviating firm such that its profits become zero. In the unique equilibrium, the regulator has to impose neither taxes nor subsidies and both firms invest. The emissions are zero and the production quantities $q_{1}$ and $q_{2}$ are the same as without regulation. Hence, there are no product market distortions due to regulation. We next investigate the announcement of the tax rate.

\subsection{The Tax/Subsidy Mechanism with the Announce- ment of the Tax Rate}

\subsubsection{Only One Firm Invests}

Again we start with the case where the first firm is the only firm investing. The tax rate $t^{a n n}$ for firm 2 is announced. To simplify the exposition we assume that the regulator announces the lowest tax rate $t^{a n n}$, if he is indifferent to varying taxes. ${ }^{11}$ Note that the second firm will choose $q_{2}$ such that $\Pi_{2} \geq 0$, given $t^{a n n}$, because it can always ensure $\Pi_{2}=0$ by setting $q_{2}=0$. Thus we can set the tax rate $t$ equal to $t^{a n n}$ and the subsidy rate $s$ is determined by the self-financing condition:

$$
s=t \frac{q_{2}}{q_{1}} .
$$

\footnotetext{
${ }^{11}$ The regulator is indifferent to different tax rates, if the product market outcome and subsidy and tax levels are identical.
} 
Now, given $t$ and choice $q_{2}$, the overall subsidies $t q_{2}$ are of a lump-sum nature for the first firm. Therefore net profits are given by

$$
\Pi_{1}=(1-b Q-c) q_{1}+t q_{2}-K, \quad \Pi_{2}=(1-b Q-c-t) q_{2} .
$$

The unique Nash equilibrium of the Cournot game yields

$$
q_{1}=\frac{1-c+t}{3 b}, \quad q_{2}=\frac{1-c-2 t}{3 b},
$$

where $t$ is situated in the interval $\left[0, \frac{1-c}{2}\right]$. This leads to the following net profits:

$$
\Pi_{1}=\frac{(1-c)^{2}+5(1-c) t-5 t^{2}}{9 b}-K, \quad \Pi_{2}=\frac{(1-c-2 t)^{2}}{9 b} .
$$

Clearly, the profit of the second firm is decreasing in $t$ :

$$
\frac{\partial \Pi_{2}}{\partial t}=-4 \frac{1-c-2 t}{9 b}=-\frac{4}{3} q_{2} \leq 0 \quad \forall t \in\left[0, \frac{1-c}{2}\right] .
$$

The tax rate $\frac{1-c}{2}$, denoted by $t^{*}$, is the smallest tax rate that yields $\Pi_{2}=0$. Since the announcement of a tax rate higher than $t^{*}$ yields the same outcome as the announcement of $t^{*}$, the regulator announces $t^{*}$ if social welfare is increasing in $t$. If the regulator announces $t^{*}$, we find that

$$
\begin{gathered}
q_{1}=\frac{1-c}{2 b}, \quad q_{2}=0, \\
\Pi_{1}=\frac{(1-c)^{2}}{4 b}-K, \quad \Pi_{2}=0 .
\end{gathered}
$$

Therefore when $t=t^{*}$ the investing firm essentially becomes a monopolist and no emissions occur.

Again we examine how social welfare depends on $t$. The sum of consumer surplus and producer surplus amounts to

$$
S+P=\frac{b}{2}\left(\frac{2(1-c)-t}{3 b}\right)^{2}+\frac{(1-c)^{2}+5(1-c) t-5 t^{2}+(1-c-2 t)^{2}}{9 b}
$$

and is monotonically decreasing in $t$, since

$$
\frac{\partial(S+P)}{\partial t}=-\frac{1-c+t}{9 b}=-\frac{1}{3} q_{1}<0 \quad \forall t \in\left[0, t^{*}\right] .
$$


The social damage of emissions $D(E)$ is monotonically increasing in $E$ and the emissions $E$ are monotonically decreasing in $t$, since

$$
\frac{\partial E}{\partial t}=-\frac{2 a}{3 b}<0 \quad \forall t \in\left[0, t^{*}\right]
$$

As a consequence, social welfare is monotonically increasing in $t$ if

$$
\frac{\partial W}{\partial t}=-\frac{1-c+t}{9 b}+\frac{2 a}{3 b} \frac{\partial D(E)}{\partial E(t)}>0 \quad \forall t \in\left[0, t^{*}\right]
$$

which is equivalent to the condition

$$
\frac{\partial D(E)}{\partial E(t)}>\frac{1-c+t}{6 a} \quad \forall t \in\left[0, t^{*}\right]
$$

and fulfilled if

$$
\min _{0 \leq t \leq t^{*}} \frac{\partial D(E)}{\partial E(t)}>\frac{1-c}{4 a} .
$$

We call condition (45) the large marginal damage (LMD) assumption.

It may occur that $\frac{\partial W}{\partial t}<0$ for all $t \in\left[0, t^{*}\right]$, which is equivalent to the condition

$$
\frac{\partial D(E)}{\partial E(t)}<\frac{1-c+t}{6 a} \quad \forall t \in\left[0, t^{*}\right]
$$

and fulfilled if

$$
\max _{0 \leq t \leq t^{*}} \frac{\partial D(E)}{\partial E(t)}<\frac{1-c}{6 a} .
$$

In this case, the regulator will choose $t=0$ if one firm has invested since welfare losses from product-market distortions dominate welfare losses from emissions. We call condition (47) the small marginal damage (SMD) assumption.

\subsubsection{Equilibria}

Now we derive the subgame perfect equilibrium of the four-stage game. An equilibrium is now characterized by $I_{1}, I_{2}, q_{1}, q_{2}$, and possibly $\tau$ or $t$. The regulator will announce the tax rate $t=t^{*}$ if, in the case of $I_{1} \neq I_{2}$,

$$
\frac{\partial W}{\partial t} \geq 0 \quad \forall t \in\left[0, t^{*}\right]
$$


In the appendix we prove the following proposition:

Proposition 2 Assume OFI and LMD.

1. There exists a unique subgame perfect equilibrium:

$$
\left(I_{1}=I_{2}=K, q_{1}=q_{2}=\frac{1-c}{3 b}\right)
$$

supported by

$$
\tau=t^{0}, t=t^{*}
$$

2. If $I_{1} \neq I_{2}$, then $\forall t \in\left[0, t^{*}\right]$

$$
\begin{gathered}
\frac{\partial(S(Q)+P(Q))}{\partial t}<0, \\
\frac{\partial E}{\partial t}<0
\end{gathered}
$$

and

$$
\frac{\partial W}{\partial t}>0
$$

Proposition 2 indicates that announcing the tax rate in the OFI situation will yield the investment of both firms as long as LMD is fulfilled. But, as indicated in the next proposition, LMD is never fulfilled when HUP holds.

Proposition 3 LMD is violated if HUP holds.

The proof of proposition 3 is given in the appendix. Proposition 3 indicates that the regulator supposedly has to announce a smaller tax rate than $t^{*}$ if HUP holds. If the marginal damage of emissions is so severe that LMD is fulfilled, then the standard emission taxation and the tax/subsidy mechanism, with the announcement of the tax rate, yield the investment of both firms.

In contrast to subsidies, there are instances where the credible tax rate is zero if one firm has invested. The reason stems from the asymmetric reactions of firms to self-financing subsidies and tax rates. In the former 
case, subsidies for the investing firm drive the profit, but not the output ${ }^{12}$, of the non-investing firm to zero. In contrast, announcing $t^{*}$ reduces the profit and the output of the non-investing firm to zero. Therefore, using tax rates makes product-market distortions more severe than using subsidies. This may induce the regulator to implement $t=0$, if the marginal damage of emissions is not too high.

\subsection{Announcement of Taxes or Subsidies?}

In the next step, we compare subsidy and tax announcement. Comparing propositions 1 and 2 immediately yields

Proposition 4 Assume OFI. Then, ${ }^{13}$

1. if $K<\frac{9}{5} \pi_{1}^{K K}-\pi_{1}^{00}$ and $L M D$ holds, announcing the subsidy rate $\left(s^{*}\right)$ or the tax rate ( $\left.t^{*}\right)$ uniquely implements $I_{1}=I_{2}=K$.

2. if $K<\frac{9}{5} \pi_{1}^{K K}-\pi_{1}^{00}$ and $S M D$ holds, announcing the subsidy rate ( $s^{*}$ ) uniquely implements $I_{1}=I_{2}=K$, whereas announcing the tax rate does not.

3. if $K>\frac{9}{5} \pi_{1}^{K K}-\pi_{1}^{00}$ and $L M D$ holds, announcing the tax rate ( $\left.t^{*}\right)$ uniquely implements $I_{1}=I_{2}=K$, whereas announcing the subsidy rate does not.

4. if $K>\frac{9}{5} \pi_{1}^{K K}-\pi_{1}^{00}$ and $S M D$ holds, announcing the subsidy rate or the tax rate does not uniquely implement $I_{1}=I_{2}=K$.

Proposition 4 indicates that announcing the subsidy rate has the advantage that $s^{*}$ is always credible.

There are situations in which investment by both firms is socially optimal, but the credible tax rate $t$ is zero (see Example 1). However, announcing subsidy rates generates fewer profits from investment than announcing tax

\footnotetext{
${ }^{12}$ In equilibrium holds $q_{1}=\frac{2 \sqrt{5}}{5-\sqrt{5}} q_{2}$.

${ }^{13}$ Moreover all standard examples with linear or quadratic damage functions fulfill the cases 1, 2 or 4 . We have not found an example yet to support case 3 .
} 
rates if $I_{1} \neq I_{2}$. That is why announcing tax rates can uniquely induce $I_{1}=I_{2}=K$ for a larger range of investment parameters. But if $\frac{4}{5} \pi_{1}^{K K} \geq \pi_{1}^{00}$, the announcement of the subsidy rate also yields investment by both firms for all investment costs that fulfill OFI (in particular: $K<\pi_{1}^{K K}$ ). $t^{0}$ is comparatively high if the marginal damage of emissions is comparatively high; and $\frac{4}{5} \pi_{1}^{K K} \geq \pi_{1}^{00}$ holds if $t^{0}$ is at least $1-\frac{2}{\sqrt{5}}$.

However, even if announcing the subsidy or the tax rate uniquely implement $I_{1}=I_{2}=K$, and yield equal equilibrium welfare, some important differences in out-of-equilibrium behavior remain. These are summarized in proposition 5 .

Proposition 5 Assume OFI, $K<\frac{9}{5} \pi_{1}^{K K}-\pi_{1}^{00}$ and LMD. If $I_{1} \neq I_{2}$, then

1. emissions are higher under $s^{*}$ than under $t^{*}$; in particular, announcing $t^{*}$ leads to zero emissions.

2. the sum of consumer and producer surplus under $s^{*}$ is higher than under $t^{*}$.

The proof of proposition 5 is given in the appendix. Again, the asymmetric reactions of investing and non-investing firms to subsidy or tax announcements explain the result:

- Both announcing the tax rate and announcing the subsidy rate raises the production volume of the investing firm at the expense of the noninvesting firm.

- Announcing the tax rate lowers the aggregate production volume whereas announcing the subsidy rate raises the aggregate production volume.

$s^{*}$ does not affect the quantity choice of the non-investing firm (say firm 1) directly since $s^{*} q_{1}$ is of a lump-sum nature for firm 2. But $s^{*}$ directly raises the production quantity of the firm investing. Taxation creates different effects. $t^{*}$ has no direct influence on the quantity choice of the investing firm, whereas it has influence on the quantity choice of the non-investing firm. 
Note that the use of the tax/subsidy mechanism is only better than no regulation in terms of social welfare, if the emission reduction potential of the abatement technology is high enough in comparison with the investment costs.

\subsection{The Linear Case and an Example}

In this section we discuss the linear case in more detail and obtain the remarkable result that for $D(E)=d E$ with $d>0$ the hold-up problem is always solvable.

At first we calculate the tax rates $t^{0}$ and $t^{K}$ of the standard emissiontaxation regime. The social welfare in the case of $I_{1} \neq I_{2}$ amounts to

$$
\begin{aligned}
W= & \frac{b}{2}\left(\frac{2(1-c)-t^{K}}{3 b}\right)^{2}+\left(t^{K}-d a\right) \frac{1-c-2 t^{K}}{3 b} \\
& +\frac{\left(1-c+t^{K}\right)^{2}+\left(1-c-2 t^{K}\right)^{2}}{9 b}-K .
\end{aligned}
$$

The first order condition yields the interior solution of $t^{K}$ :

$$
\begin{gathered}
\frac{\partial W}{\partial t^{k}}=\frac{6 a d-(1-c)-t^{K}}{9 b}=0 \\
\Longrightarrow t^{K}=6 a d-(1-c)
\end{gathered}
$$

The general solution of $t^{K}$ is

$$
t^{K}=\left\{\begin{array}{ll}
0 & \text { if } \quad a d \leq \frac{1-c}{6} \\
6 a d-(1-c) & \text { if } \quad a d \in\left(\frac{1-c}{6}, \frac{1-c}{4}\right) \\
\frac{1-c}{2} & \text { if } \quad a d \geq \frac{1-c}{4}
\end{array} .\right.
$$

If $I_{1}=I_{2}=0$, then the social welfare is given by

$$
W=\frac{b}{2}\left(2 \frac{1-c-t^{0}}{3 b}\right)^{2}+2\left(t^{0}-d a\right) \frac{1-c-t^{0}}{3 b}+2 \frac{\left(1-c-t^{0}\right)^{2}}{9 b} .
$$

The interior solution of $t^{0}$ is calculated as follows:

$$
\frac{\partial W}{\partial t^{0}}=\frac{6 a d-2(1-c)-4 t^{0}}{9 b}=0
$$




$$
\Longrightarrow t^{0}=\frac{3 a d-(1-c)}{2}
$$

The general solution of $t^{0}$ is

$$
t^{0}= \begin{cases}0 & \text { if } \quad a d \leq \frac{1-c}{3} \\ \frac{3 a d-(1-c)}{2} & \text { if } \quad a d \in\left(\frac{1-c}{3}, 1-c\right) \\ 1-c & \text { if } \quad a d \geq 1-c\end{cases}
$$

In the appendix we prove the following proposition:

Proposition 6 Assume HUP and $D(E)=d E$ with $d>0$. Then, announcing the subsidy rate $s^{*}$ uniquely implements $I_{1}=I_{2}=K$.

Proposition 6 indicates that if marginal damage is constant, the holdup problem can always be solved by the tax/subsidy mechanism with the announcement of $s^{*}$. In the next step we provide an example which illustrates proposition 6 .

Example $1 D(E)=E, \quad a=\frac{1}{10}, \quad c=0, \quad K=\frac{1}{100 b}$

First, we derive $t^{0}$. From (56) follows

$$
t^{0}=0
$$

since

$$
a d=\frac{1}{10} \leq \frac{1-c}{3}=\frac{1}{3} .
$$

Next, we derive $t^{K}$. We calculate $t^{K}$ by using equation (52):

$$
t^{K}=0
$$

The production quantities $q_{1}^{00}$ and $q_{1}^{K 0}$ are the same as $q_{1}^{K K}$, because the two tax rates $t^{0}$ and $t^{K}$ are zero.

HUP exists since the following three inequalities are fulfilled:

$$
\begin{aligned}
K & =\frac{1}{100 b}<\pi_{1}^{K K}=\frac{1}{9 b} \\
W_{2}-\max \left\{W_{0}, W_{1}\right\} & =-2 K-\max \left\{-D\left(a q_{1}^{K K}\right)-K,-D\left(2 a q_{1}^{K K}\right)\right\}=\frac{7}{300 b}>0 \\
K & =\frac{1}{100 b}>\min \left\{\pi_{1}^{K 0}-\pi_{1}^{00}, \pi_{2}^{K K}-\pi_{2}^{K 0}\right\}=0
\end{aligned}
$$


Moreover, the credible tax rate (of the tax/subsidy mechanism with the announcement of the tax rate) is zero since SMD holds:

$$
\max _{0 \leq t \leq t^{*}} \frac{\partial D}{\partial E(t)}=1<\frac{1-c}{6 a}=\frac{5}{3}
$$

$K<\frac{9}{5} \pi_{1}^{K K}-\pi_{1}^{00}$ is fulfilled since

$$
K=\frac{1}{100 b}<\frac{9}{5} \pi_{1}^{K K}-\pi_{1}^{00}=\frac{4}{5} \pi_{1}^{K K}=\frac{4}{45 b} .
$$

Therefore both firms will invest if the regulator announces $s^{*}$. But if the regulator announces the credible tax rate, no firm will invest. Thus the regulator must announce $s^{*}$.

\section{Bertrand Competition}

In this section we examine Bertrand competition. Using the standard framework, assume that the two firms respectively choose their prices, denoted by $p_{1}$ and $p_{2}$. Consumers only buy the product from the firm with the lower price. If the prices of both firms are equal, both firms receive half of the total demand. To simplify the exposition, we again assume a tie-breaking rule: A firm will choose to stay in the market, if it is indifferent between exiting and staying in the market.

\subsection{Self-financing Mechanism with Two Firms Invest- ing}

Due to the standard Bertrand result, without regulatory intervention, firms make zero gross profit in the fourth stage, independent of the investment decisions in the second stage. Therefore, no firm will invest without regulation. Thus, with regulation via tax/subsidy mechanisms, price competition with homogeneous products cannot induce both firms to invest. This is, of course, also the case under standard emission taxation. If both firms have invested, gross product-market profits are zero in the fourth stage, thus the net profits are negative since neither taxes nor subsidies apply. A firm can then avoid negative profits by not investing. We summarize this simple observation in the following proposition. 
Proposition 7 There exists no self-financing mechanism (and no mechanism with revenues) that yields $I_{1}=I_{2}=K$.

However, it is possible to induce investment by one firm via tax/subsidy mechanisms. This will be discussed in the next subsection.

\subsection{Self-financing Mechanism with Only One Firm In- vesting}

We denote the total demand, the first firm's demand and the second firm's demand by $N, N_{1}$ and $N_{2}$ respectively.

We consider first the fourth stage. Assume momentarily $I_{1}=K \neq I_{2}$. Assume also that the regulator uses the tax/subsidy mechanism with the announcement of tax rate $t^{a n n}$. Again the regulator is assumed to announce the lowest tax rate if different tax rates are optimal with respect to the maximization of $W$. Note that firm 2 will choose $p_{2}$ such that $\Pi_{2} \geq 0$, given $t^{a n n}$, because it can always ensure $\Pi_{2}=0$ by setting $p_{2}$ such that $N_{2}=0$. As a consequence, we have $t^{a n n}=t$ if both firms choose their equilibrium prices. The net profits are given by

$$
\Pi_{1}=\left(p_{1}-c\right) N_{1}+t N_{2}-K, \quad \Pi_{2}=\left(p_{2}-c-t\right) N_{2} .
$$

Suppose that industry profits $(p-c) N(p)$ have a unique maximum at the monopoly price $p^{m}$, and are monotonically increasing in $p$ for all $p \in[c$, $\left.p^{m}\right] \cdot{ }^{14}$ Suppose further that

$$
0 \leq t \leq p^{m}-c
$$

We obtain:

Lemma 1 There exists a unique equilibrium in stage 4, if the regulator announces the tax rate $t$ :

$$
\begin{aligned}
p_{1} & =p_{2}=c+t \\
N_{1} & =N_{2}=\frac{N(c+t)}{2} \\
\Pi_{1} & =t N(c+t)-K, \quad \Pi_{2}=0
\end{aligned}
$$

\footnotetext{
${ }^{14}$ If $N(p)$ is differentiable, the assumption is equivalent to the elasticity condition $\left|\frac{(p-c) \partial N(p) / \partial p}{N(p)}\right|<1$.
} 
The proof of lemma 1 is given in the appendix. The important point of lemma 1 is that, even if one firm is taxed, both firms produce under the tax/subsidy mechanism. By taking into account the induced subsidies, the first firm does not want to undercut the second firm by its price setting. The following very simple example illustrates the economic forces at work.

Example $2 N=1-\frac{p}{10}$

The monopoly price is

$$
p^{m}=5+\frac{c}{2} .
$$

Assume that the first firm is the only firm investing. In equilibrium, profit of the first firm is denoted by $\Pi_{1}^{E Q U}$ and given by

$$
\Pi_{1}^{E Q U}=t\left(1-\frac{c+t}{10}\right)-K .
$$

If the first firm deviates and undercuts the second firm with $p_{1}=c+t-\varepsilon$, its profit is denoted by $\Pi_{1}^{D E V}$ and given by

$$
\Pi_{1}^{D E V}=(t-\varepsilon)\left(1-\frac{c+t-\varepsilon}{10}\right)-K .
$$

$\Pi_{1}^{E Q U}$ is at least as high as $\Pi_{1}^{D E V}$ if

$$
0 \leq t \leq 5-\frac{c+\varepsilon}{2}
$$

which is fulfilled if

$$
0 \leq t \leq p^{m}-c
$$

The situation is quite different if subsidies are announced. Assume now the regulator uses the tax/subsidy mechanism with the announcement of the subsidy rate $s^{a n n}$. For any realized subsidy rate $s$, the net profits of the two firms are then given by

$$
\Pi_{1}=\left(p_{1}-c+s\right) N_{1}-K, \quad \Pi_{2}=\left(p_{2}-c\right) N_{2}-s N_{1} .
$$

We obtain: 
Lemma 2 The implemented subsidy rate $s$ is always zero.

The proof of lemma 2 is given in the appendix. The important difference in comparison with the announcement of the tax rate is that subsidies cannot be used by the regulator to achieve investment by one firm. The non-investing firm can either undercut the other firm and avoid subsidies, or it can make zero profits, which leads to $s=0$ as well.

We next examine the overall game. Proposition 8 contains the main results.

Proposition 8 1. Assume $K<\left(p^{m}-c\right) N\left(p^{m}\right)$, and that the regulator announces the tax rate. Then, there exist tax rates $t \leq p^{m}-c$ such that the unique equilibrium in stage 2 is $I_{1} \neq I_{2}$.

2. No equilibrium with $I_{1} \neq I_{2}$ exists under the announcement of subsidies.

The proof of proposition 8 is given in the appendix. Proposition 8 indicates that the regulator has to announce a tax rate $t$ larger than $\frac{K}{N(c+t)}$ and smaller than $p^{m}-c$ if he wants one firm to invest. The social welfare maximizing tax rate, denoted by $t^{*}$, balances benefits and costs in the following way. Suppose that $I_{1} \neq I_{2}$. Increasing $t$ in $\left.] \frac{K}{N(c+t)}, p^{m}-c\right]$ implies lowering output $Q=N(c+t)$ and lowering emissions $E=\frac{N(c+t)}{2}$. This causes a decline in consumer surplus and emission damage. It also causes higher producer surplus, since $t N(c+t)-K$ is increasing in $t$ for all $t \leq p^{m}-c$. $t^{*}$ balances environmental and output distortions.

\section{Conclusions}

Our analysis suggests that announcing the subsidy rate is preferable to announcing the tax rate if competition is soft, i.e. firms compete in quantities. The opposite is true if competition is fierce, i.e. firms compete in prices. We suggest that self-financing tax/subsidy mechanisms might be applied as feebate systems in the automotive industry.

Our analysis can be extended in several ways. To begin with, we have assumed that investment in clean technologies can reduce emissions to zero. 
A more general feature would be the assumption that the emissions per unit of output of a firm investing are $a_{I}$ and of a non-investing firm are $a_{N I}$ $\left(a_{I}<a_{N I}\right)$. One can verify, very tediously, that our results under Cournot competition are qualitatively the same, as long as $2 a_{I}<a_{N I}$. For $2 a_{I} \geq a_{N I}$, which describes a situation where emission reductions through investments are low, there is, however, no guarantee that $s^{*}$ is the credible subsidy rate. The reason for that result is that the emissions $E$ are monotonically increasing (fix) in $s$ if $2 a_{I}>a_{N I}\left(2 a_{I}=a_{N I}\right)$. Hence, announcing $s^{*}$ remains optimal as long as investments lead to substantial reduction in emissions.

Further, announcing the tax rate has one additional advantage, not present in our model, over announcing the subsidy rate. When setting taxes or subsidies, regulators may have to cope with significant uncertainty. Suppose the regulator announces a slightly higher subsidy rate than $s^{*}$, or a slightly higher tax rate than $t^{*}$ under Cournot competition. As discussed earlier in this paper, in the case of subsidies this requires that the implemented rate is lower than the announced rate, whereas an announced tax rate higher than $t^{*}$ has no additional effect and could be implemented. Therefore, announcing the tax rate seems to be less dependent on small uncertainty than announcing the subsidy rate.

Overall, the tax/subsidy scheme appears to be a viable regulation mechanism to achieve socially desirable investments by firms supplementary to the standard tools in environmental regulation. 


\section{Appendix}

\subsection{Proof of Proposition 1}

We show existence and uniqueness by working backwards.

1. Stage 4

Both firms choose their production quantities.

(a) Both firms have invested:

Since investment outlays are sunk, Cournot competition yields

$$
q_{i}=q_{i}^{K K}=\frac{1-c}{3 b}, \quad i=1,2 .
$$

(b) Neither firm has invested:

The firms are taxed with the rate $\tau$. Thus, Cournot competition results in

$$
q_{i}=q_{i}^{00}=\frac{1-c-\tau}{3 b}, \quad i=1,2 .
$$

(c) One firm (say firm 1) has invested:

As discussed in subsection 4.2.1, the firms choose

$$
q_{1}=\frac{1-c+2 s}{3 b}, \quad q_{2}=\frac{1-c-s}{3 b} .
$$

2. Stage 3

The regulator chooses $\tau$ or $s$ to maximize social welfare. His decision depends on the investment decisions of the firms.

(a) Both firms have invested:

No taxes or subsidies are imposed, since there are no emissions.

(b) Neither firm has invested:

The regulator maximizes social welfare by imposing the emission $\operatorname{tax} \tau=t^{0}$. 
(c) One firm (say firm 1) has invested:

It has been shown in subsection 4.2.1 that the regulator maximizes social welfare by announcing the subsidy rate $s=s^{*}$.

3. Stage 2

The firms decide whether to invest. We consider the first firm's decision.

(a) Suppose $I_{2}=0$. The net profit of the first firm is

$$
\Pi_{1}=\frac{(1-c)^{2}}{5 b}-K
$$

if it invests. In the case of no investment, firm 1 obtains

$$
\Pi_{1}=\frac{\left(1-c-t^{0}\right)^{2}}{9 b} .
$$

(b) Suppose $I_{2}=K$. The profit of the first firm is

$$
\Pi_{1}=\pi_{1}^{K K}-K=\frac{(1-c)^{2}}{9 b}-K
$$

if it invests. If it does not invest, its profit amounts to

$$
\Pi_{1}=0 \text {. }
$$

Note that there are no incentives to deviate from this equilibrium in order to violate the self-financing condition by lowering $q_{1}$, given $s^{*}$ is fixed, since then taxation occurs at the maximum possible level $\left(\Pi_{1}=0\right)$. The first firm is indifferent between $q_{1}=\frac{1-c+2 s}{3 b}$ and a smaller $q_{1}$. As we have assumed with the tie-breaking rule in section 4 , in this situation the first firm will choose the highest possible quantity, which is $q_{1}=\frac{1-c+2 s}{3 b}$.

Therefore, to invest is a strictly dominant strategy for the first firm if

$$
\begin{aligned}
& K<\pi_{1}^{K K} \text { and } \\
& K<\frac{(1-c)^{2}}{5 b}-\frac{\left(1-c-t^{0}\right)^{2}}{9 b}=\frac{9}{5} \pi_{1}^{K K}-\pi_{1}^{00} .
\end{aligned}
$$

The subgame perfect equilibrium is unique, hence the first point is shown. The second point has been established in subsection 4.2.1. 


\subsection{Proof of Proposition 2}

Again we establish existence and uniqueness of the equilibrium by working backwards.

1. Stage 4

Both firms choose their production quantities.

(a) Both firms have invested:

Again we have

$$
q_{i}=q_{i}^{K K}=\frac{1-c}{3 b}, \quad i=1,2
$$

(b) Neither firm has invested:

As in the subsidy case we have

$$
q_{i}=q_{i}^{00}=\frac{1-c-\tau}{3 b}, \quad i=1,2 .
$$

(c) One firm (say firm 1) has invested:

As discussed in subsection 4.3.1, firms choose the production quantities

$$
q_{1}=\frac{1-c+t}{3 b}, \quad q_{2}=\frac{1-c-2 t}{3 b} .
$$

2. Stage 3

The regulator chooses $\tau$ and $t$ to maximize social welfare. The only difference to the subsidy announcement is the case $I_{1} \neq I_{2}$, where it has been shown in subsection 4.3.1 that the regulator maximizes social welfare by announcing the tax rate $t=t^{*}$ if LMD holds.

3. Stage 2

The firms decide whether to invest. Suppose LMD. We consider the first firm's decision:

(a) Suppose $I_{2}=0$. The net profit of the first firm in the case of an investment is

$$
\Pi_{1}=\frac{(1-c)^{2}}{4 b}-K .
$$


If it does not invest, its profit amounts to

$$
\Pi_{1}=\frac{\left(1-c-t^{0}\right)^{2}}{9 b} .
$$

(b) Suppose $I_{2}=K$. The profit of the first firm is

$$
\Pi_{1}=\pi_{1}^{K K}-K=\frac{(1-c)^{2}}{9 b}-K
$$

if it invests. In the case of no investment, its profit is

$$
\Pi_{1}=0
$$

Thus, $I_{1}=K$ is a strictly dominant strategy for the first firm since

$$
K<\pi_{1}^{K K}<\frac{9}{4} \pi_{1}^{K K}-\pi_{1}^{00}=\frac{(1-c)^{2}}{4 b}-\frac{\left(1-c-t^{0}\right)^{2}}{9 b} .
$$

Therefore, the subgame perfect equilibrium is unique, which establishes the first point. The second point has been shown in subsection 4.3.1.

\subsection{Proof of Proposition 3}

The credible tax rate of the tax/subsidy mechanism $(t)$ equals the tax rate of the standard-emission-taxation tax rate in the case of $I_{1} \neq I_{2}\left(t^{k}\right)$. The reason for this is that the first order conditions of welfare maximization with respect to $t$ and to $t^{k}$ are the same, and are given by

$$
\frac{\partial W}{\partial t}=-\frac{1-c+t}{9 b}+\frac{2 a}{3 b} \frac{\partial D(E)}{\partial E(t)}=-\frac{1-c+t^{k}}{9 b}+\frac{2 a}{3 b} \frac{\partial D(E)}{\partial E\left(t^{k}\right)}=\frac{\partial W}{\partial t^{k}} .
$$

Suppose $t=t^{*}=\frac{1-c}{2}$. From $t=t^{k}$ follows $t^{k}=\frac{1-c}{2}$. HUP implies

$$
K>\min \left\{\pi_{1}^{K 0}-\pi_{1}^{00}, \pi_{2}^{K K}-\pi_{2}^{K O}\right\} \geq \min \left\{\frac{5}{4} \pi_{1}^{K K}, \pi_{1}^{K K}\right\}=\pi_{1}^{K K},
$$

which does not fulfill HUP. Therefore $t$ has to be smaller than $t^{*}$ and LMD cannot hold. 


\subsection{Proof of Proposition 5}

Suppose OFI, $K<\frac{9}{5} \pi_{1}^{K K}-\pi_{1}^{00}$, LMD and $I_{1} \neq I_{2}$. The credible tax (subsidy) rate is $t^{*}\left(s^{*}\right)$.

If the regulator announces the tax (subsidy) rate, the resulting emissions are denoted by $E_{t}\left(E_{s}\right)$ and given by

$$
\begin{aligned}
& E_{t} \equiv 0 \\
& E_{s} \equiv a \frac{(5-\sqrt{5})(1-c)}{10 b},
\end{aligned}
$$

which illustrates the first part. The sum of consumer and producer surplus is denoted by $(S+P)_{t}$ or $(S+P)_{s}$ if the regulator announces the tax rate or the subsidy rate, respectively. We find that

$$
\begin{aligned}
(S+P)_{t} & =\frac{b}{2}\left(\frac{1-c}{2 b}\right)^{2}+\frac{(1-c)^{2}}{4 b} \\
(S+P)_{s} & =\frac{b}{2}\left(\frac{(5-\sqrt{5})(1-c)}{10 b}+\frac{1-c}{\sqrt{5} b}\right)^{2}+\frac{(1-c)^{2}}{5 b} .
\end{aligned}
$$

The sum of consumer and producer surplus is larger, if the regulator announces $s^{*}$ instead of $t^{*}$, if and only if

$$
(S+P)_{s}-(S+P)_{t}>0 \Longleftrightarrow \frac{(2 \sqrt{5}-1)(1-c)^{2}}{40 b}>0
$$

which always holds, thus establishing the second part.

\subsection{Proof of Proposition 6}

Suppose $t^{k}=\frac{1-c}{2}$. HUP implies

$$
K>\min \left\{\pi_{1}^{K 0}-\pi_{1}^{00}, \pi_{2}^{K K}-\pi_{2}^{K O}\right\} \geq \min \left\{\frac{5}{4} \pi_{1}^{K K}, \pi_{1}^{K K}\right\}=\pi_{1}^{K K},
$$

which does not fulfill HUP. Therefore $t^{K}$ has to be smaller than $\frac{1-c}{2}$, and

$$
d a<\frac{1-c}{4}
$$


must hold (See (52)).

HUP implies

$$
\begin{aligned}
& W_{2}>W_{0} \\
\Longrightarrow & W_{2}>W^{\text {noreg }, 0} \\
\Longleftrightarrow & D\left(2 q_{1}^{K K}\right)>2 K \\
\Longleftrightarrow & K<d a \frac{1-c}{3 b} .
\end{aligned}
$$

$W^{\text {noreg, } 0}$ denotes the social welfare, if no firm has invested and no regulation is introduced.

Suppose $s^{*}$ does not imply $I_{1}=I_{2}=K$. From proposition 1 , it must hold that

$$
\begin{gathered}
K \geq \frac{9}{5} \pi_{1}^{K K}-\pi_{1}^{00} \\
\Longrightarrow K \geq \frac{4}{5} \pi_{1}^{K K}=\frac{4(1-c)^{2}}{45 b} .
\end{gathered}
$$

Inequality (96) and inequality (92) together imply

$$
K<\frac{(1-c)^{2}}{12 b}
$$

Inequality (98) and inequality (99) together imply

$$
\frac{4(1-c)^{2}}{45 b}<\frac{(1-c)^{2}}{12 b}
$$

which leads to the contradiction $48<45$. Therefore $s^{*}$ implies $I_{1}=I_{2}=K$.

\subsection{Proof of Lemma 1}

In the equilibrium, the first firm obtains

$$
t \frac{N(c+t)}{2}
$$

tax revenues from the second firm. The only critical deviation to be checked is

$$
p_{1}=c+t-\varepsilon, \quad 0<\varepsilon<<1 .
$$


Then the first firm would capture the whole market, but would not receive any taxes from the second firm. Deviating yields the net profit

$$
\Pi_{1}=(t-\varepsilon) N(c+t-\varepsilon)-K
$$

of the first firm, which is less than in equilibrium as long as

$$
t N(c+t) \geq(t-\varepsilon) N(c+t-\varepsilon)
$$

or equivalent if

$$
(p-c) N(p) \geq(p-c-\varepsilon) N(p-\varepsilon) .
$$

Condition (105) is fulfilled for all $p \in\left[c, p^{m}\right]$, since $(p-c) N(p)$ is monotonically increasing in $p$ for all $p \in\left[c, p^{m}\right]$. Therefore, condition (104) is fulfilled for all $t \in\left[0, p^{m}-c\right]$.

Note that due to our tie-breaking rule, the second firm will stay in the market.

\subsection{Proof of Lemma 2}

The reaction function of the second firm is denoted by $p_{2}\left(p_{1}\right)$, and is given by

$$
p_{2}\left(p_{1}\right)=\left\{\begin{array}{ll}
p_{1}-\varepsilon & \text { if } p_{1}>c \\
p_{1} & \text { if } p_{1}=c \\
>c & \text { else }
\end{array} .\right.
$$

In the first case $\left(p_{1}>c\right)$, the second firm undercuts $p_{1}$ to obtain the total demand and thus to avoid taxation, since $t=\min \left\{s^{a n n} N_{1}, \max \left\{\Pi_{2}^{*}, 0\right\}\right\} / N_{2}$ becomes zero due to $N_{1}=0$. Accordingly, we have $s=0$. The second firm chooses $p_{2}=p_{1}$ if the first firm chooses the price $c$ (second case). The subsidy rate $s=\min \left\{s^{a n n}, \max \left\{\frac{\Pi_{2}^{*}}{N_{1}}, 0\right\}\right\}$ becomes zero again, since $\Pi_{2}^{*}=0$. The tie-breaking rule ensures that the second firm does not exit. In the latter case $\left(p_{1}<c\right)$, the second firm offers a price higher than $c$ to avoid $\Pi_{2}<0$. Again we have $s=0$. To sum up, the implemented subsidy rate $s$ is always zero. 


\subsection{Proof of Proposition 8}

Suppose the regulator announces the tax rate $t$ close to $p^{m}-c$. Then

$$
K<t N(c+t) .
$$

The reaction function of a firm (say firm 1 ) is denoted by $I_{1}\left(I_{2}\right)$ and is given by

$$
I_{1}\left(I_{2}\right)=\left\{\begin{array}{ll}
0 & \text { if } I_{2}=K \\
K & \text { else }
\end{array} .\right.
$$

In the first case $\left(I_{2}=K\right)$, firm 1 does not invest, since no investment yields a net profit of zero instead of $-K$. In the latter case $\left(I_{2}=0\right)$, firm 1 invests to ensure a positive net profit instead of a net profit of zero, which illustrates the first part.

The second part of proposition 8 follows from lemma 2 , since no investment yields a net profit of zero instead of $-K$, which is the profit per firm if both firms have invested. 


\section{References}

[1] Bernow, S., 2002, Program design features for feebate initiative: Survey of existing feebate programs, Tellas Institute Memorandum.

[2] DTI, 2003, New and renewable energy: prospects for the 21st century, Department of Trade and Industry, 29 August.

[3] Gersbach, H., 2002, How to get firms to invest: A simple solution to the hold-up problem in regulation, Review of Economic Design 7, 45-56.

[4] Gersbach, H. and A. Glazer, 1999, Markets and regulatory hold-up problems, Journal of Environmental Economics and Management 37(2), 151164.

[5] Gilbert, R. J. and Newberry, D. M., 1994, The dynamic efficiency of regulatory constitutions, Rand Journal of Economics 25(4), 538-554.

[6] Hart, O., 1995, Firms, Contracts, and Financial Structure, Oxford University Press.

[7] Helm, D. C. Hepburn and R. Mash, 2003, Time-inconsistent environmental policy and optimal delegation, University of Oxford: department of economics discussion paper series.

[8] HLB Decision Economics Inc., 1999: Transportation and climate change: Assessment of feebate systems for Canada, Ottawa.

[9] Joskow, P. L., 1987, Contract duration and relationship-specific investments: Empirical evidence from coal markets, American Economic Review $77(1), 168-185$.

[10] Jung, C., Krutilla, K. and Boyd, R, 1996, Incentives for advanced pollution abatement technology at the industry level: An evaluation of policy alternatives, Journal of Environmental Economics and Management 30(1), 95-111.

[11] Klein, B., Crawford, R. G. and Alchian, A. A., 1978, Vertical integration appropriable rents, and the competitive contracting process, Journal of Law and Economics 21, 297-326. 
[12] Laffont, J. J. and Tirole, J., 1996, Pollution permits and environmental innovation, Journal of Public Economics 62, 127-140.

[13] Levy, B. and Spiller, P. T., 1997, A framework for resolving the regulatory problem In: Levy and Spiller: Regulations, institutions, and commitment: Comparative studies of telecommunications, New York: Cambridge University Press.

[14] Matsuyama, K., 1990, Perfect equilibrium in a trade liberalization game, American Economic Review 80, 480-492.

[15] Milliman, S. R. and Prince, R., 1989, Firm incentives to promote technological change in pollution control, Journal of Environmental Economics and Management 17(3), 247-265.

[16] Moore, J., 1992, Implementation, contracts and renegotiation in environments with complete information In: Laffont, J. J.: Advances in economic theory: Sixth world congress, Cambridge: Cambridge University Press, 182-281.

[17] New York Times, May 27, 1998.

[18] Requate, T., 1995, Incentives to adopt new technologies under different pollution-control policies, International Tax and Public Finance 2, 295317.

[19] Requate, T. and Unold, W., 2003, Environmental policy incentives to adopt advanced abatement technology - will the true ranking please stand up?, European Economic Review 47, 125-146.

[20] Salant, D. J. and Woroch, G. A., 1992, Trigger price regulation, Rand Journal of Economics 23(1), Spring, 29-51.

[21] Staiger, R. W. and Tabellini, G., 1987, Discretionary trade policy and excessive protection, American Economic Review 77, 823-837.

[22] Tornell, A., 1991, Time inconsistency of protection programs, Quarterly Journal of Economics, August, 963-974.

[23] Train, K. E., W. B. Davis and M. D. Levine, 1997, Fees and rebates on new vehicles: Impacts on fuel efficiency, carbon dioxide emissions, and consumer surplus, Transportation Research E 33(1), 1 - 13. 
[24] Urbiztondo, S., 1994, Investment without regulatory commitment - the case of elastic demand, Journal of Regulatory Economics 6(1), 87-96.

[25] Varian, H. L., 1994, A solution to the problem of externalities when agents are well-informed, American Economic Review 84(5), 1278-1293.

[26] Weimann, J., 1995, Umweltökonomik, Berlin, Springer.

[27] Williamson, O. E., 1983, Credible commitments: Using hostages to support exchange, American Economic Review 83, 519-540. 


\section{CESifo Working Paper Series}

(for full list see www.cesifo-group.de)

1465 François Ortalo-Magné and Sven Rady, Heterogeneity within Communities: A Stochastic Model with Tenure Choice, May 2005

1466 Jukka Pirttilä and Sanna Tenhunen, Pawns and Queens Revisited: Public Provision of Private Goods when Individuals make Mistakes, May 2005

1467 Ernst Fehr, Susanne Kremhelmer and Klaus M. Schmidt, Fairness and the Optimal Allocation of Ownership Rights, May 2005

1468 Bruno S. Frey, Knight Fever - Towards an Economics of Awards, May 2005

1469 Torberg Falch and Marte Rønning, The Influence of Student Achievement on Teacher Turnover, May 2005

1470 John Komlos and Peter Salamon, The Poverty of Growth with Interdependent Utility Functions, May 2005

1471 Hui Huang, Yi Wang, Yiming Wang, John Whalley and Shunming Zhang, A Trade Model with an Optimal Exchange Rate Motivated by Current Discussion of a Chinese Renminbi Float, May 2005

1472 Helge Holden, Lars Holden and Steinar Holden, Contract Adjustment under Uncertainty, May 2005

1473 Kai A. Konrad, Silent Interests and All-Pay Auctions, May 2005

1474 Ingo Vogelsang, Electricity Transmission Pricing and Performance-Based Regulation, May 2005

1475 Spiros Bougheas and Raymond Riezman, Trade and the Distribution of Human Capital, June 2005

1476 Vesa Kanniainen, Seppo Kari and Jouko Ylä-Liedenpohja, The Start-Up and Growth Stages in Enterprise Formation: The "New View" of Dividend Taxation Reconsidered, June 2005

1477 M. Hashem Pesaran, L. Vanessa Smith and Ron P. Smith, What if the UK had Joined the Euro in 1999? An Empirical Evaluation Using a Global VAR, June 2005

1478 Chang Woon Nam and Doina Maria Radulescu, Effects of Corporate Tax Reforms on SMEs' Investment Decisions under the Particular Consideration of Inflation, June 2005

1479 Panos Hatzipanayotou, Sajal Lahiri and Michael S. Michael, Globalization, CrossBorder Pollution and Welfare, June 2005 
1480 John Whalley, Pitfalls in the Use of Ad valorem Equivalent Representations of the Trade Impacts of Domestic Policies, June 2005

1481 Edward B. Barbier and Michael Rauscher, Trade and Development in a Labor Surplus Economy, June 2005

1482 Harrie A. A. Verbon and Cees A. Withagen, Tradable Emission Permits in a Federal System, June 2005

1483 Hendrik Hakenes and Andreas Irmen, On the Long-Run Evolution of Technological Knowledge, June 2005

1484 Nicolas Schmitt and Antoine Soubeyran, A Simple Model of Brain Circulation, June 2005

1485 Carsten Hefeker, Uncertainty, Wage Setting and Decision Making in a Monetary Union, June 2005

1486 Ondřej Schneider and Jan Zápal, Fiscal Policy in New EU Member States - Go East, Prudent Man!, June 2005

1487 Christian Schultz, Virtual Capacity and Competition, June 2005

1488 Yvan Lengwiler and Elmar Wolfstetter, Bid Rigging - An Analysis of Corruption in Auctions, June 2005

1489 Johannes Becker and Clemens Fuest, Does Germany Collect Revenue from Taxing Capital Income?, June 2005

1490 Axel Dreher and Panu Poutvaara, Student Flows and Migration: An Empirical Analysis, June 2005

1491 Bernd Huber and Marco Runkel, Interregional Redistribution and Budget Institutions under Asymmetric Information, June 2005

1492 Guido Tabellini, Culture and Institutions: Economic Development in the Regions of Europe, July 2005

1493 Kurt R. Brekke and Michael Kuhn, Direct to Consumer Advertising in Pharmaceutical Markets, July 2005

1494 Martín Gonzalez-Eiras and Dirk Niepelt, Sustaining Social Security, July 2005

1495 Alfons J. Weichenrieder, (Why) Do we need Corporate Taxation?, July 2005

1496 Paolo M. Panteghini, S-Based Taxation under Default Risk, July 2005

1497 Panos Hatzipanayotou and Michael S. Michael, Migration, Tied Foreign Aid and the Welfare State, July 2005 
1498 Agata Antkiewicz and John Whalley, BRICSAM and the Non-WTO, July 2005

1499 Petr Hedbávný, Ondřej Schneider and Jan Zápal, A Fiscal Rule that has Teeth: A Suggestion for a 'Fiscal Sustainability Council' underpinned by the Financial Markets, July 2005

1500 J. Atsu Amegashie and Marco Runkel, Sabotaging Potential Rivals, July 2005

1501 Heikki Oksanen, Actuarial Neutrality across Generations Applied to Public Pensions under Population Ageing: Effects on Government Finances and National Saving, July 2005

1502 Xenia Matschke, Costly Revenue-Raising and the Case for Favoring Import-Competing Industries, July 2005

1503 Horst Raff and Nicolas Schmitt, Why Parallel Trade may Raise Producers Profits, July 2005

1504 Alberto Bisin and Piero Gottardi, Efficient Competitive Equilibria with Adverse Selection, July 2005

1505 Peter A. Zadrozny, Necessary and Sufficient Restrictions for Existence of a Unique Fourth Moment of a Univariate GARCH(p,q) Process, July 2005

1506 Rainer Niemann and Corinna Treisch, Group Taxation, Asymmetric Taxation and Cross-Border Investment Incentives in Austria, July 2005

1507 Thomas Christiaans, Thomas Eichner and Ruediger Pethig, Optimal Pest Control in Agriculture, July 2005

1508 Biswa N. Bhattacharyay and Prabir De, Promotion of Trade and Investments between China and India: The Case of Southwest China and East and Northeast India, July 2005

1509 Jean Hindriks and Ben Lockwood, Decentralization and Electoral Accountability: Incentives, Separation, and Voter Welfare, July 2005

1510 Michelle R. Garfinkel, Stergios Skaperdas and Constantinos Syropoulos, Globalization and Domestic Conflict, July 2005

1511 Jesús Crespo-Cuaresma, Balázs Égert and Ronald MacDonald, Non-Linear Exchange Rate Dynamics in Target Zones: A Bumpy Road towards a Honeymoon - Some Evidence from the ERM, ERM2 and Selected New EU Member States, July 2005

1512 David S. Evans and Michael Salinger, Curing Sinus Headaches and Tying Law: An Empirical Analysis of Bundling Decongestants and Pain Relievers, August 2005

1513 Christian Keuschnigg and Martin D. Dietz, A Growth Oriented Dual Income Tax, July 2005 
1514 Fahad Khalil, David Martimort and Bruno Parigi, Monitoring a Common Agent: Implications for Financial Contracting, August 2005

1515 Volker Grossmann and Panu Poutvaara, Pareto-Improving Bequest Taxation, August 2005

1516 Lars P. Feld and Emmanuelle Reulier, Strategic Tax Competition in Switzerland: Evidence from a Panel of the Swiss Cantons, August 2005

1517 Kira Boerner and Silke Uebelmesser, Migration and the Welfare State: The Economic Power of the Non-Voter?, August 2005

1518 Gabriela Schütz, Heinrich W. Ursprung and Ludger Wößmann, Education Policy and Equality of Opportunity, August 2005

1519 David S. Evans and Michael A. Salinger, Curing Sinus Headaches and Tying Law: An Empirical Analysis of Bundling Decongestants and Pain Relievers, August 2005

1520 Michel Beine, Paul De Grauwe and Marianna Grimaldi, The Impact of FX Central Bank Intervention in a Noise Trading Framework, August 2005

1521 Volker Meier and Matthias Wrede, Pension, Fertility, and Education, August 2005

1522 Saku Aura and Thomas Davidoff, Optimal Commodity Taxation when Land and Structures must be Taxed at the Same Rate, August 2005

1523 Andreas Haufler and Søren Bo Nielsen, Merger Policy to Promote 'Global Players'? A Simple Model, August 2005

1524 Frederick van der Ploeg, The Making of Cultural Policy: A European Perspective, August 2005

1525 Alexander Kemnitz, Can Immigrant Employment Alleviate the Demographic Burden? The Role of Union Centralization, August 2005

1526 Baoline Chen and Peter A. Zadrozny, Estimated U.S. Manufacturing Production Capital and Technology Based on an Estimated Dynamic Economic Model, August 2005

1527 Marcel Gérard, Multijurisdictional Firms and Governments' Strategies under Alternative Tax Designs, August 2005

1528 Joerg Breitscheidel and Hans Gersbach, Self-Financing Environmental Mechanisms, August 2005 